\title{
SISTEM INFORMASI SURVEI KEPUASAN PENGGUNA LAYANAN PADA KPPN BENGKULU MENGGUNAKAN BAHASA PEMROGRAMAN PHP DAN DATABASE MYSQL
}

\author{
Arif Hamdani Puta ${ }^{1)}$, Asnawati ${ }^{2}$, Ricky Zulfiandry ${ }^{3)}$ \\ ${ }^{1,2,3}$ Dosen Tetap Program Studi Sistem Informasi Fakultas IImu Komputer Universitas \\ Dehasen Bengkulu
}

Email: ${ }^{1) ~)}$ ira123@yahoo.ac.id; ${ }^{2)}$ sopian21@gmail.com; ${ }^{3)}$ ricky.zulfiandry@unived.ac.id

\section{How to Cite :}

Arif Hamdani Puta, Asnawati, Ricky Zulfiandry. 2020. SISTEM INFORMASI SURVEI KEPUASAN PENGGUNA LAYANAN PADA KPPN BENGKULU MENGGUNAKAN BAHASA PEMROGRAMAN PHP DAN DATABASE MYSQL. GATOTKACA Journal.DOI:https://doi.org/10.37638/gatotkaca.1.1.29-41

\section{ARTICLE HISTORY}

Received [12Januari 2020]

Revised [16 Februari 2020]

Accepted [20 Maret 2020]

\section{KEYWORDS}

Information System, Satisfaction Survey, UserService, KPPN Bengkulu, PHP, MYSQL

This is an open access article under the $C C-B Y-S A$ license

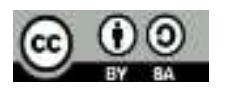

\section{ABSTRAK}

Selama ini untuk mengetahui kepuasan pengguna layanan, akan dilakukan survei kepuasan pengguna layanan dengan memberikan lembaran pertanyaan yang diisi oleh pengguna layanan pada saat berada di KPPN Bengkulu. Pertanyaan yang diberikan cukup banyak karena penilaian dilakukan dengan mengisi pertanyaan pada 5 kategori penilaian yaitu kinerja layanan pencairan dana, kinerja layanan bimbingan dan konsultasi, kinerja layanan konfirmasi surat setoran, kinerja layanan rekonsiliasi laporan keuangan (realisasi APBN), sarana dan prasarana. Dengan banyaknya pertanyaan yang harus diisi oleh pengguna layanan, sehingga membutuhkan waktu yang cukup lama untuk mengisi survei tesebut., dan survei tersebut juga tidak dapat dibawa pulang oleh pengguna layanan. Sistem informasi survei kepuasan pengguna layanan pada KPPN Bengkulu merupakan suatu aplikasi berbaris web yang dapat diakses dimana saja dan kapan saja secara online melalui link url website : www.kkpnbengkulusurvei.online. Sistem informasi survei kepuasan pengguna layanan pada KPPN Bengkulu dapat membantu proses survei yang dilakukan oleh penguna layanan setiap tahunnya. Hasil penilaian survei dari pengguna layanan akan dikalkulasikan untuk mendapatkan output berupa grafik dan hasil perhitungan rata-raa skor kepuasan pengguna layanan. Dari hasil kuisioner tersebut dapat disimpulkan bahwa sistem informasi survei kepuasan 
pengguna layanan dapat membantu pengguna layanan dalam mengisi survei, dan saran yang diberikan dari hasil kuisioner yaitu sistem informasi survei kepuasan pengguna layanan agar dapat disosialisasikan keseluruh penggun layanan.

\section{ABSTRACT}

User satisfaction survey by giving the question sheets filled by service users while in KPPN Bengkulu. The questions were given quite a lot because the assessment was done by filling in the questions on the 5 categories of assessments, namely the performance of the disbursement service, the performance of the guidance and consulting services, the performance of the deposit confirmation mail service, the performance of financial statement reconciliation service (realization of $A P B N)$, facilities and infrastructure. With so many questions that service users need to fill in, it takes a long time to complete the survey, and the survey also cannot be taken home by the service user. Information system of customer service satisfaction survey on KPPN Bengkulu is a web marching application that can be accessed anywhere and anytime by online through website url link: www.kkpnbengkulusurvei.online. Information system of service user satisfaction survey on KPPN Bengkulu can assist the survey process conducted by the service users every year. Survey assessment results from users of the service will be calculated to obtain graphical output and calculation results of user service satisfaction scores. From the results of the questionnaire can be concluded that the information system of service user satisfaction survey can help service users in filling the survey, and advice given from the results of the questionnaire is a system of customer service satisfaction survey information to be socialized throughout the service users.

\section{PENDAHULUAN}

Kantor Pelayanan dan Perbendaharaan Negara (KPPN) Bengkulu merupakan lembaga instansi yang selalu kedatangan pengunjung untuk tujuan berbeda-beda yang dilayani 
oleh Satuan Kerja KPPN Bengkulu. Dimana setiap pengunjung punya berbagai kepuasan dan keluhan atas kinerja pelayanan satuan kerja KPPN Bengkulu.

Selama ini untuk mengetahui kepuasan pengguna layanan, setiap 6 bulan akan dilakukan survei kepuasan pengguna layanan dengan memberikan lembaran pertanyaan yang diisi oleh pengguna layanan pada saat berada di KPPN Bengkulu. Pertanyaan yang diberikan cukup banyak karena penilaian dilakukan dengan mengisi pertanyaan pada 5 kategori penilaian yaitu kinerja layanan pencairan dana, kinerja layanan bimbingan dan konsultasi, kinerja layanan konfirmasi surat setoran, kinerja layanan rekonsiliasi laporan keuangan (realisasi APBN), sarana dan prasarana. Dengan banyaknya pertanyaan yang harus diisi oleh pengguna layanan, sehingga membutuhkan waktu yang cukup lama untuk mengisi survei tersebut, dan survei tersebut juga tidak dapat dibawa pulang oleh pengguna layanan.

Oleh karena itu dibutuhkan suatu aplikasi yang dapat membantu KPPN Bengkulu dalam melakukan survei kepada pengguna layanan, dimana aplikasi ini dapat diakses darimana saja dan kapan saja karena terhubung dengan internet. Namun tidak semua yang dapat memberikan penilaian, karena hak akses dibatasi hanya pengguna layanan yang terdaftar di KPPN Bengkulu yang dapat memberikan penilaian terhadap survei yang diberikan.

Untuk mendukung pembuatan aplikasi tersebut, maka penulis menggunakan bahasa pemrograman PHP untuk membuat interface dari aplikasi, dan database MySQL sebagai media penyimpanan hasil dari proses pengolahan data yang dilakukan. Aplikasi nantinya akan di publish ke internet sehingga pengguna layanan dapat mengakses aplikasi ini darimana saja dan kapansaja untuk memberikan penilaian terhadap survei yang diberikan. Namun sebelum pengguna layanan dapat memberikan penilaian, pengguna layanan harus melakukan login terlebih dahulu pada aplikasi.

\section{LANDASAN TEORI}

\section{A. Sistem Informasi}

Sistem Informasi (SI) adalah kombinasi dari teknologi informasi dan aktivitas orang yang menggunakan teknologi itu untuk mendukung operasi dan manajemen. Dalam arti yang sangat luas, istilah sistem informasi sering digunakan merujuk kepada interaksi antara orang, proses algoritmik, data, dan teknologi (Intan, 2015 : 161).

Sistem informasi adalah suatu sistem kerja yang kegiatannya ditujukan untuk pengolahan (menangkap, transmisi, menyimpan, mengambil, memanipulasi, dan menampilkan) informasi. Dengan demikian, sistem informasi antar berhubungan dengan sistem data di satu sisi dan sistem aktivitas di sisi lain. Sistem informasi adalah satu bentuk komunikasi sistem dimana data yang mewakili dan diproses sebagai bentuk dari memori sosial. Sistem informasi juga dapat dianggap sebagai bahasa semi formal yang mendukung manusia dalam pengambilan keputusan dan tindakan (Intan, 2015 : 161).Sistem Informasi (SI) adalah kombinasi dari teknologi informasi dan aktivitas orang yang menggunakan teknologi itu untuk mendukung operasi dan manajemen. Dalam arti yang sangat luas, istilah sistem informasi sering digunakan merujuk kepada interaksi antara orang, proses algoritmik, data, dan teknologi (Intan, $2015: 161)$.

\section{B. Pengaruh Kualitas Layanan Terhadap Kepuasan Pelanggan}

Salah satu kemungkinan hubungan yang banyak disepakati adalah kepuasan membantu pelanggan dalam merevisi persepsinya terhadap kualitas jasa. Dasar pemikirannya seperti dikemukakan oleh Fandy Tjiptono dan Gregorius Chandra, (2005 : 209) dalam Harto, (2015 : 22) yaitu: 
1. Bila konsumen tidak memiliki pengalaman sebelumnya dengan suatu perusahaan, maka persepsinya terhadap kualitas jasa perusahaan tersebut akan didasarkan pada ekspektasinya.

2. Interaksi (service encounter) berikutnya dengan perusahaan tersebut akan menyebabkan konsumen memasuki proses diskonfirmasi dan merevisi persepsinya terhadap kualitas jasa.

3. Setiap interaksi tambahan dengan perusahaan itu akan memperkuat atau sebaliknya malah mengubah persepsi pelanggan terhadap kualitas jasa.

4. Persepsi terhadap kualitas jasa yang telah direvisi memodifikasi minat beli konsumen terhadap perusahaan di masa yang akan dating.

\section{Web Server XAMPP}

Untuk menguji apakah aplikasi web berjalan baik atau tidak maka diperlukan yang disebut web server. Web server ini adalah tempat dimana akan menyimpan aplikasi web, kemudian mengaksesnya melalui internet. Setiap perubahan, kecil maupun besar, upload ke web server baru setelah itu diperiksa apakah perubahan itu sudah sesuai dengan yang diinginkan atau belum (Hidayatullah, 2017 : 123).

Selain itu dibutuhkannya web server ini adalah karena untuk server side script seperti PHP, pemeriksaan baru akan tampil jika menggunakan web server. Inilah bedanya dengan client side script seperti HTML, CSS, dan Javascript yang cukup dengan browser sudah bisa tahun apakah script sudah sesuai dengan keinginan atau belum. Ada banyak web server yang bisa menjadi pilihan. Di windows ada Internet Information Service (IIS) keluaran dari Microsoft. Aplikasi web server ini sudah support ASP.NET dan PHP. Web server lain yang sangat terkenal adalah Apache. Apache sebetulnya merupakan salah satu proyek dari sebuah yayasan yang memiliki banyak proyek software gratis untuk digunakan banyak orang. Yayasan itu bernama The Apache Software Foundation.

\section{Bahasa Pemrograman PHP}

PHP Hypertext Preprocessor atau disingkat dengan PHP ini adalah suatu bahasa scripting khususnya digunakan untuk web development. Karena sifatnya yang server side scripting, maka untuk menjalankan PHP harus menggunakan web server. PHP juga dapat diintegrasikan dengan HTML, JavaScript, JQuery, Ajax. Namun, pada umumnya PHP lebih banyak digunakan bersamaan dengan file bertipe $H T M L$. Dengan menggunakan PHP dapat membuat website powerful yang dinamis dengan disertai manajemen database (Hidayatullah, $2017: 223$ ).

PHP Berbasis server side scripting. PHP sendiri dapat melakukan tugas-tugas yang dilakukan dengan mekanisme CGI seperti mengambil, mengumpulkan data dari database, men-generate halaman dinamis, atau bahkan menerima dan mengirim cookie. Dan yang menjadi keutamaan PHP itu sendiri adalah PHP bisa digunakan diberbagai operating system, diantaranya Linux, Unix, Windows, Mac Osx, Risc Os, dan operating system lainnya.

\section{METODE PENELITIAN}

Adapun metode penelitian yang digunakan penulis adalah metode pengembangan sistem. Metode pengembangan sistem yang digunakan adalah Waterfall.Adapun tahapan-tahapan metode waterfall, antara lain :

1. Analisa

Langkah ini merupakan analisa terhadap kebutuhan sistem. Pengumpulan data dalam tahap ini bisa malakukan sebuah penelitian, wawancara atau study literatur. 
2. Design

Proses desain akan menerjemahkan syarat kebutuhan ke sebuah perancangan perangkat lunak yang dapat diperkirakan sebelum dibuat coding.

3. Coding dan Testing

Coding merupakan penerjemahan design dalam bahasa yang bisa dikenali oleh komputer.

4. Penerapan

Tahapan ini bisa dikatakan final dalam pembuatan sebuah sistem. Setelah melakukan analisa, design dan pengkodean maka sistem yang sudah jadi akan digunakan oleh user.

5. Pemeliharaan

Perangkat lunak yang sudah disampaikan kepada pengguna layanan pasti akan mengalami perubahan.

\section{HASILDAN PEMBAHASAN}

Sistem informasi survei kepuasan pengguna layanan pada KPPN Bengkulu merupakan suatu aplikasi berbaris website yang dapat diakses dimana saja dan kapan saja secara online melalui link url website: www.kppnbengkulusurvei.online. Sistem informasi survei kepuasan pengguna layanan pada KPPN Bengkulu dapat membantu proses survei yang telah dilakukan oleh pengguna layanan setiap tahunnya. Hasil Penilaian survei dari pengguna layanan akan dikalkulasikan untuk mendapatkan output berupa grafik dan hasil perhitungan rata-rata nilai kepuasan pengguna layanan.

Adapun halaman antarmuka web sistem informasi kepuasan penggun layanan pada KPPN Bengkulu, antara lain:

1. Homepage Website

Homepage Website merupakan halaman antarmuka aplikasi web yang muncul pertama kali ketika membuka link website tersebut. Pada halaman Homepage terdapat menu yang dapat diakses yaitu mulai survei akan membuka halaman survei. Menu tingkat kepuasan secara umum membuka hasil dari survei tingkat kepuasan secara umum, dan menu kualitas dibandingkan tahun sebelumnya membuka hasil dari survei kualitas dibandingkan tahun sebelumnya.

Adapun halaman homepage website sistem informasi survei kepuasan pengguna layanan pada KPPN Bengkulu, terlihat pada gambar 1. 


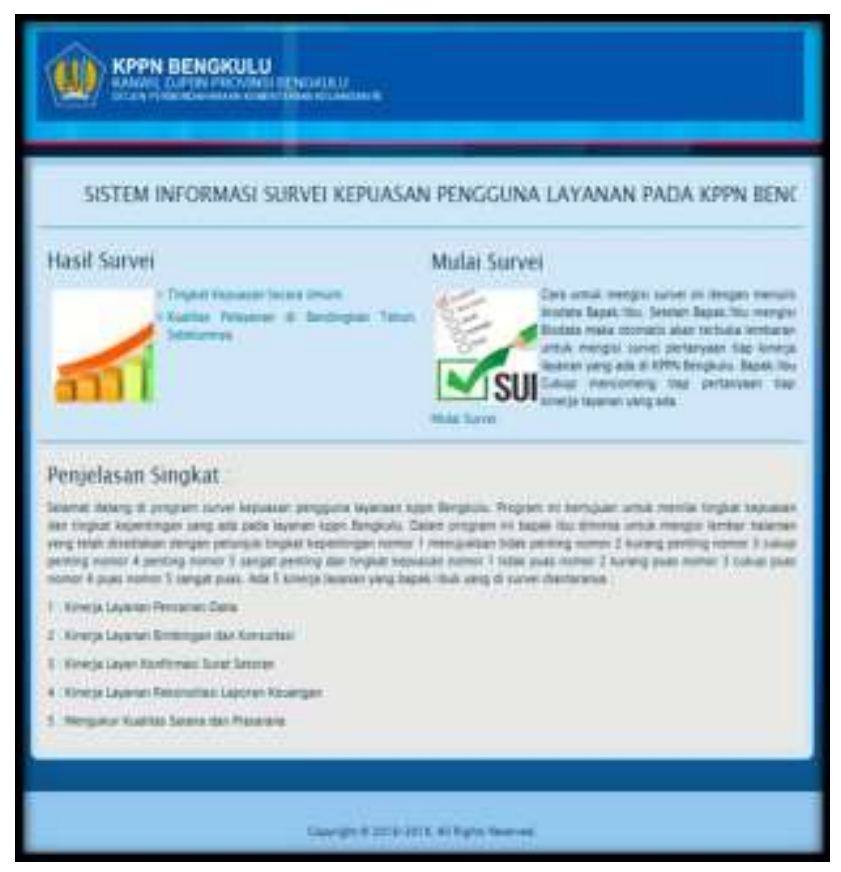

\section{Gambar 1. Halaman HomePage Website}

2. Halaman Survei Kepuasan Pengguna Layanan

Halaman survei kepuasan pengguna layanan merupakan halaman input data yang dapat diakses oleh pengguna layanan untuk memberikan survei berdasarkan pertanyaan yang diajukan. Sebelum mengisi survei tersebut, pengguna layanan wajib mengisi biodata pengguna layanan pada halaman ini, seperti tampak pada gambar 2 .

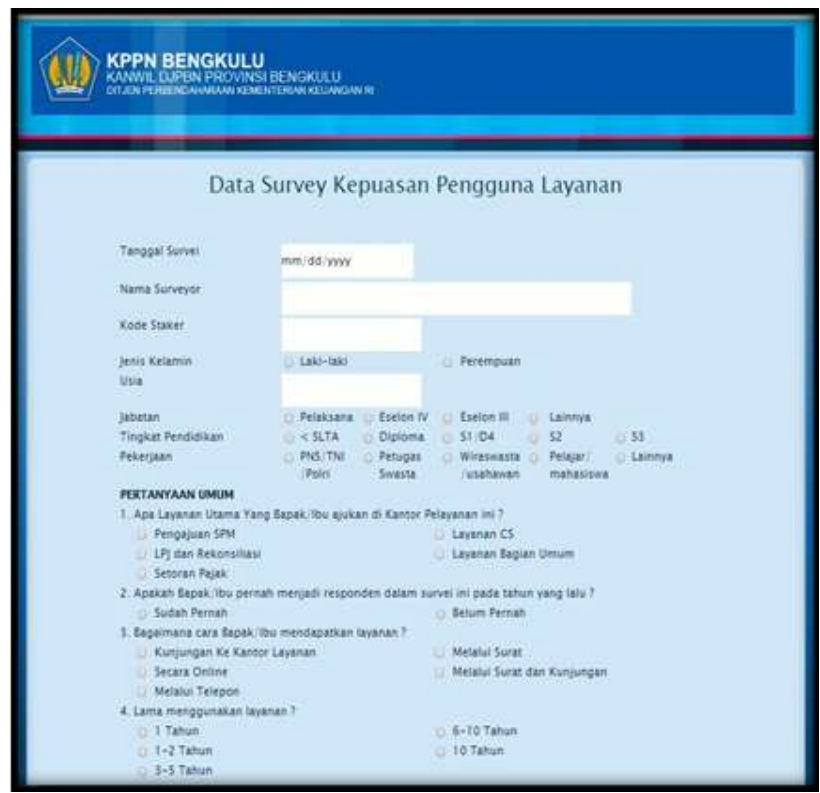

Gambar 2. Data Survei Kepuasan Pengguna Layanan

34 | Arif Hamdani Puta, Dra. Asnawati , Ricky Zulfiandry , Sistem Informasi Survei Kepuasan. 
Setelah mengisi biodata pada gambar 2 pengguna layanan dapat melakukan survei dengan cara klik tombol mulai survei, sehingga akan muncul halaman survei kepuasan pengguna layanan pencairan dana seperti tampak pada gambar 3 .

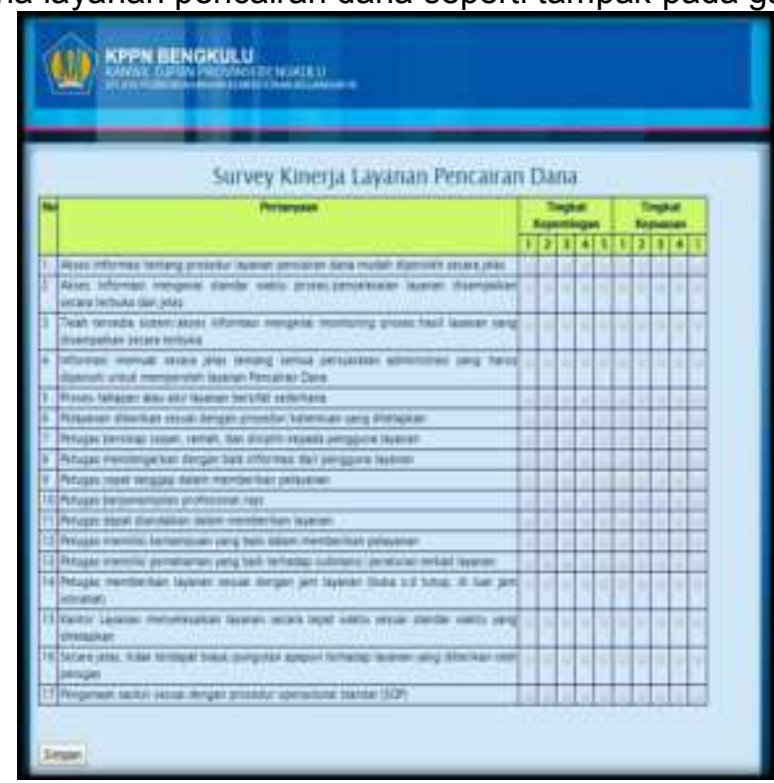

Gambar 3. Halaman Survei Kinerja Layanan Pencairan Dana

Pada gambar 3 terdapat pertanyaan yang harus diisi berdasarkan tingkat kepentingan dan tingkat kepuasan. Jika sudah melakukan survei pada kinerja layanan pencairan dana klik tombol simpan, sehingga akan muncul halaman survei kinerja layanan bimbingan dan konsultasi seperti tampak pada gambar 4.

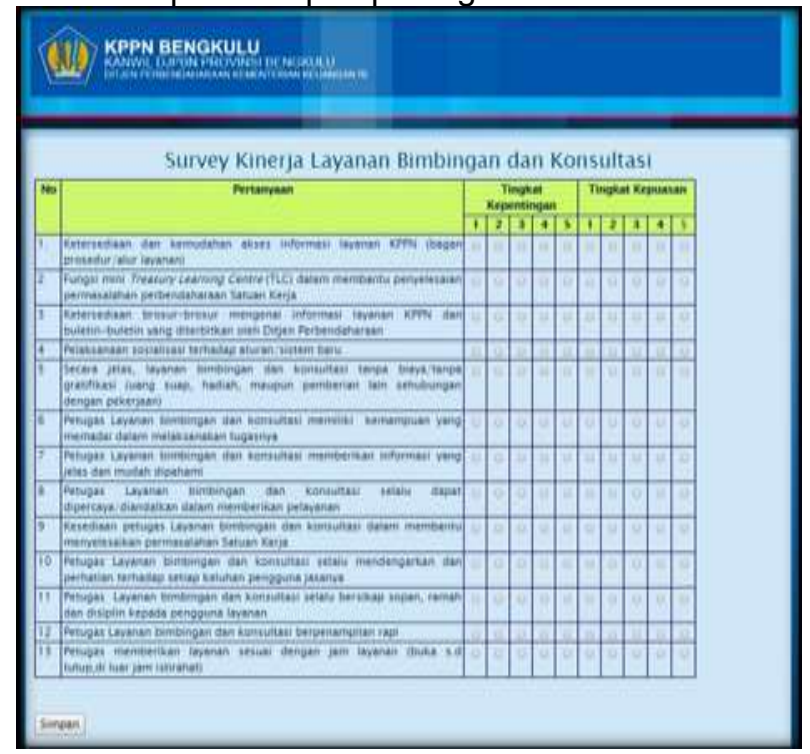

Gambar 4. Halaman Survei Kinerja layanan Bimbingan Dan Konsultasi 
3. Halaman Login Admin

Halaman login admin merupakan halaman antarmuka yang digunakan oleh admin untuk masuk ke halaman administrator dengan memasukkan username dan password yang benar. Adapun halaman login admin terlihat pada gambar 8 .

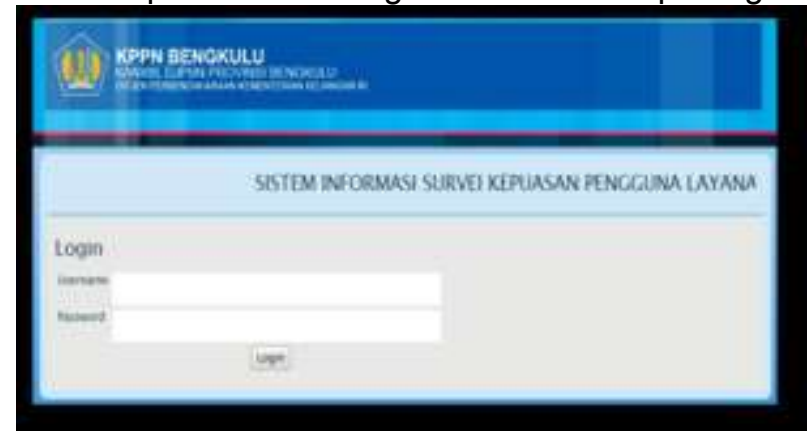

Gambar 8. Halaman Login Admin

4. Halaman Administrator

Halaman administrator merupakan halaman antarmuka web yang muncul ketika admin berhasil melakukan login pada halaman login admin. Adapun halaman administrator terlihat pada gambar 9 .

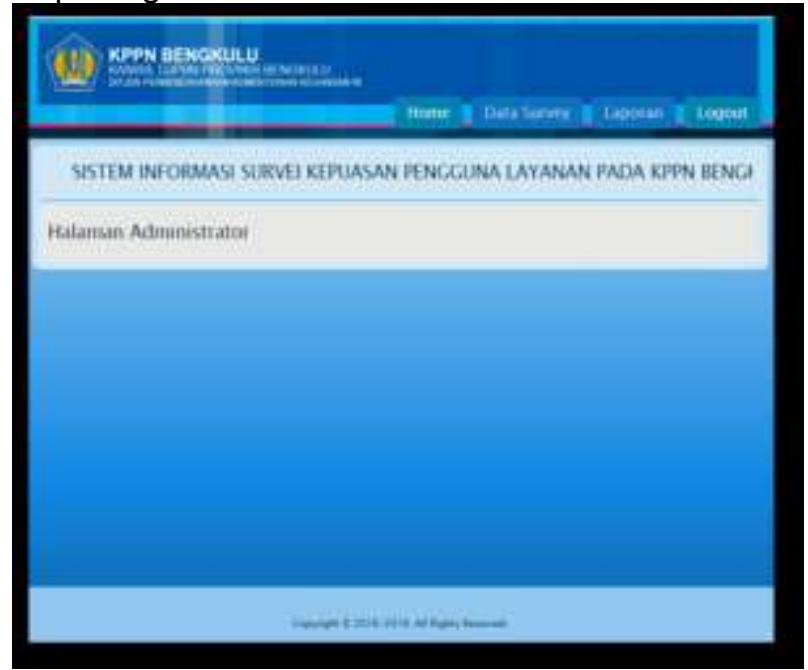

Gambar 9. Halaman Administrator

5. Halaman Data Survei Kinerja Layanan

Halaman data survei kinerja layanan merupakan halaman antarmuka web yang digunakan untuk melihat nilai dari inputan yang telah responden lakukan dihalaman survei tiap kinerja layanan.. 


\section{CAMOU RACA

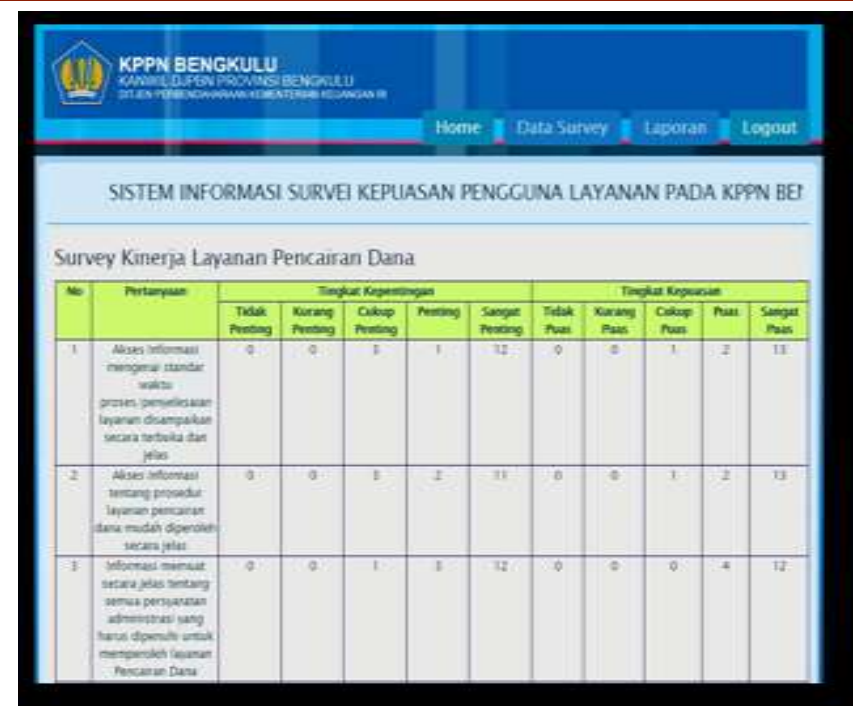

\section{Gambar 10. Data Survei Kinerja Layanan Pencairan Dana}

6. Halaman Laporan

Halaman output laporan merupakan hasil dari nilai halaman survei yang telah diisi oleh responden. Untuk melihat hasil dari output laporan dengan klik tombol pilih tahun pada tiap output laporan terlihat pada gambar 11.

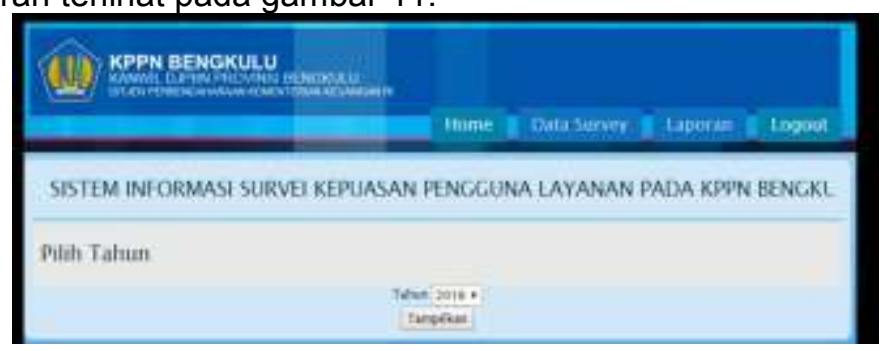

Dalam web sistem informasi survei kepuasan pengguna layanan pada KPPN Bengkulu ini terdapat 16 output diantaranya adalah laporan jumlah responden berdasarkan jenis kelamin dengan persentase laki-laki $53,3 \%$ dan perempuan $46,7 \%$ seperti yang terlihat digambar 11 . 


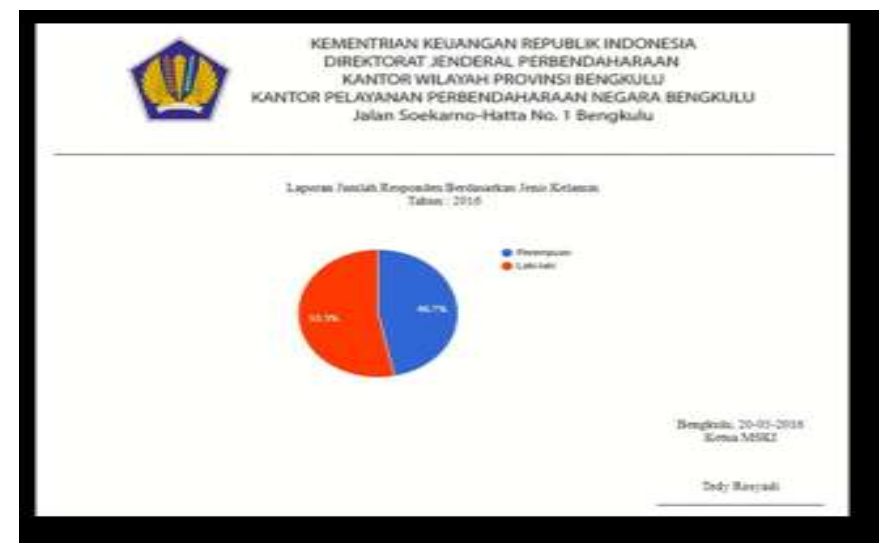

Gambar 11. Output Laporan Jumlah Responden Berdasarkan Jenis Kelamin

Gambar 12 merupakan Output laporan jumlah responden berdasarkan layanan utama merupakan hasil dari proses pengolahan data yang dijumlahkan berdasarkan layanan utama pertahunnya, yang dibuat dalam bentuk grafik.

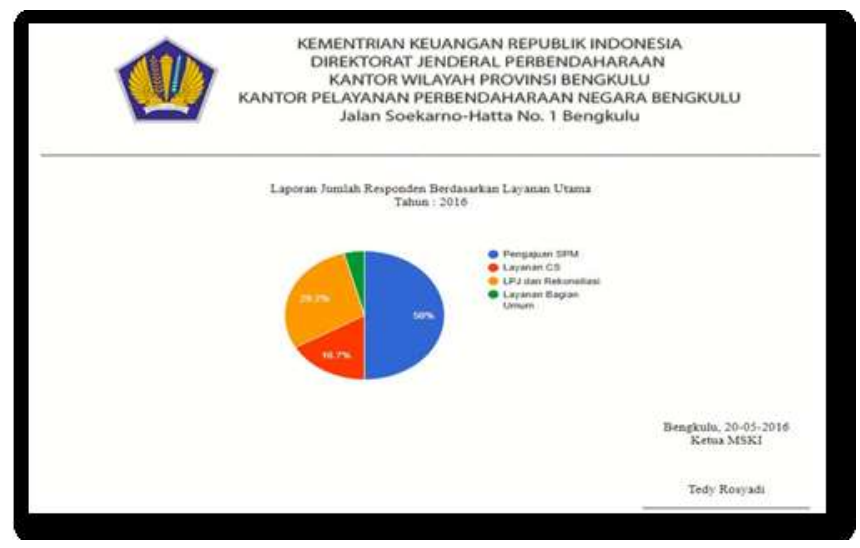

Gambar 12. Output Laporan Jumlah Responden Berdasarkan Layanan Utama

Output data laporan jumlah responden berdasarkan pengalaman mengisi survei sebelumnya merupakan hasil dari proses pengolahan data yang dijumlahkan berdasarkan layanan utama pertahunnya, yang dibuat dalam bentuk grafik. Adapun output laporan jumlah responden berdasarkan pengalaman mengisi survei sebelumnya terlihat pada gambar 13 . 


\section{G/ATOU RACA

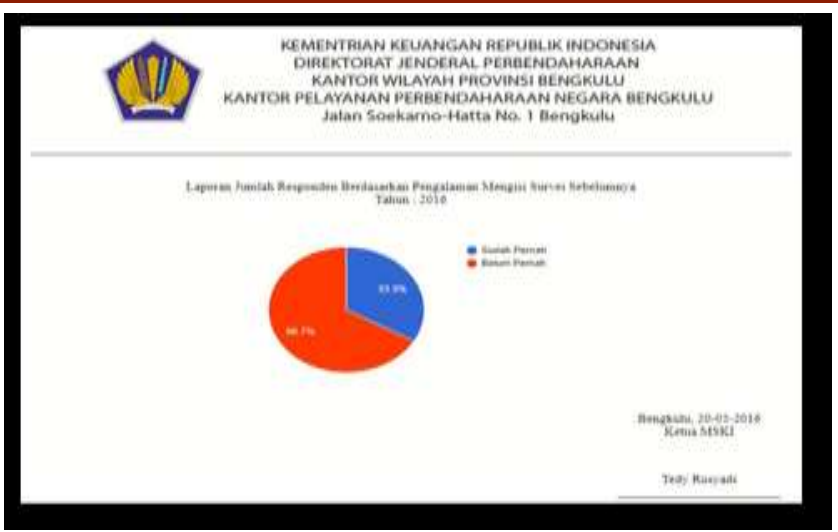

Gambar 13. Output Laporan Jumlah Responden Berdasarkan Pengalaman Mengisi Survei Sebelumnya

Gambar 14 output laporan jumlah responden berdasarkan media layanan yang digunakan merupakan hasil dari proses pengolahan data yang dijumlahkan berdasarkan layanan utama pertahunnya, yang dibuat dalam bentuk grafik. Adapun output laporan jumlah responden berdasarkan media layanan yang digunakan.

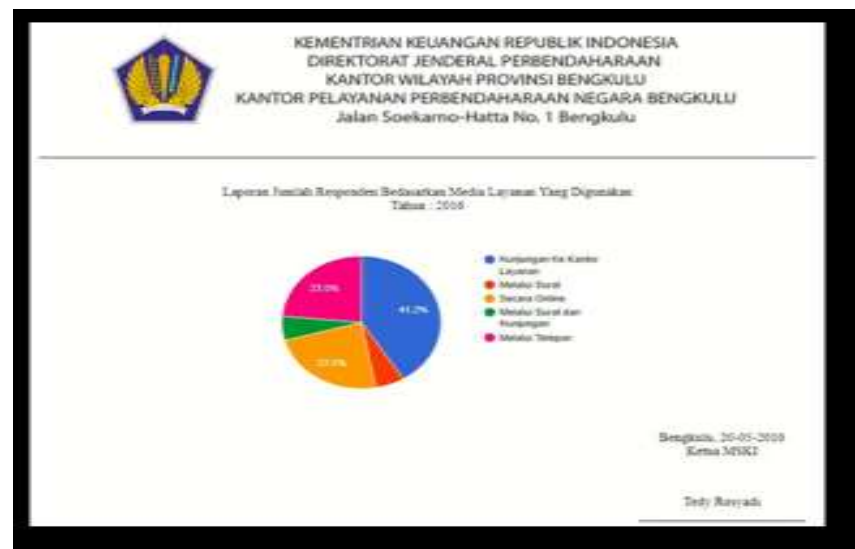

Gambar 14. Output Laporan Jumlah Responden Berdasarkan Media Layanan Yang Digunakan

Output laporan jumlah responden berdasarkan tingkat kepuasan secara umum merupakan hasil dari proses pengolahan data yang dijumlahkan berdasarkan tingkat kepuasan secara umum pertahunnya yang dibuat dalam bentuk grafik pada gambar 15. 


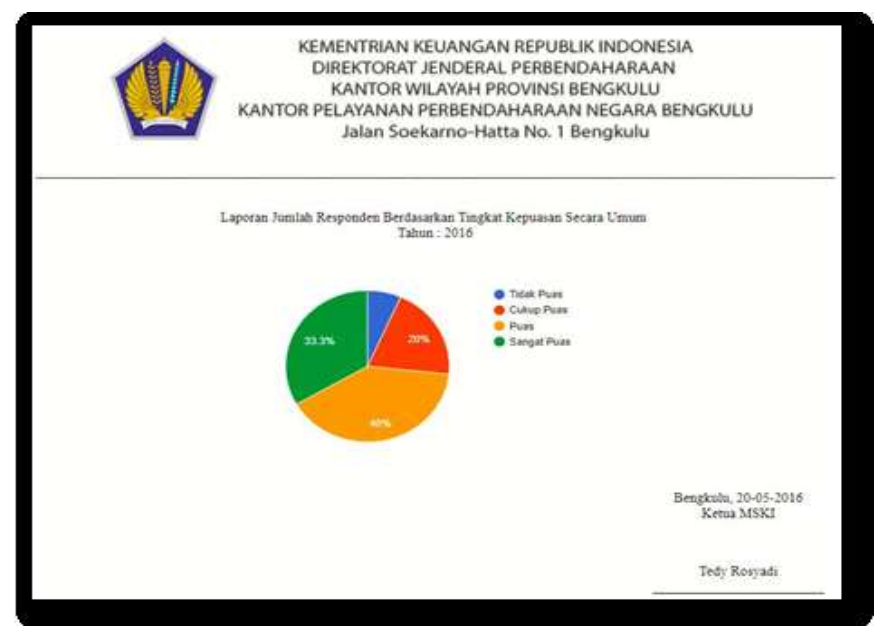

\section{Gambar 15. Output Laporan Berdasarkan Tingkat Kepuasan Secara Umum}

Dalam pengujian sistem ini, penulis menerapkan metode pengujian black box dimana akan dilakukan pendekatan yang mengamsumsikan sebuah aplikasi sebagai kotak hitam. Pengujian dilakukan dengan memberi masukkan pada form yang tersedia denga beberapa data yang dikategorikan dalam kategori data yang sah (sesuai dengan peruntukannya), dan data yang tidak sah ( data yang berfungsi untuk mengeksploitasi sistem). Selain Itu, pengujian juga dilakukan dengan memberikan kuisoner kepada 1 orang admin KPPN Bengkulu dan 15 orang pengguna layanan yang mengisi survei (data terlampir). Dari hasil kuisoner tersebut dapat disimpulkan bahwa sistem informasi survei kepuasan pengguna layanan dapat membantu pengguna layanan dalam mengisi survei, dan saran yang diberikan dari hasil kuisoner yaitu sistem informasi kepuasan pengguna layanan agar dapat disosialisasikan ke seluruh pengguna layanan dan kesimpulan bahwa sistem ini layak untuk digunakan dan diterapkan pada bagian Sistem Informasi Survei Kepuasan Pengguna Layanan Pada KPPN Bengkulu.

\section{KESIMPULAN DAN SARAN}

A. Kesimpulan

1) Sistem Informasi survei kepuasan pengguna layanan pada KPPN Bengkulu merupakan suatu aplikasi berbaris web yang dapat diakses dimana saja dan kapan saja secara online melalui link url website :www.kppnbengkulusurvei.online.

2) Sistem informasi survei kepuasan pengguna layanan pada KPPN Bengkulu dapat membantu proses survei yang dilakukan oleh pengguna layanan setiap tahunnya.

3) Hasil dari penilaian survey dari pengguna layanan akan dikalkulasikan untuk mendapatkan output berupa grafik dan hasil perhitungan rata-rata skor kepuasan pengguna layanan.

4) Dari hasil kuisioner tersebut dapat disimpulkan bahwa sistem informasi survei kepuasan pengguna layanan dapat membantu pengguna layanan dalam mengisi survei, dan saran yang diberikan dari hasil kuisioner yaitu sistem informasi survei kepuasan pengguna layanan agar dapat disosialisasikan keseluruh pengguna layanan. 


\section{B. Saran-saran}

Berdasarkan penelitian yang telah penulis lakukan di KPPN Bengkulu, maka penulis menyarankan yaitu agar dapat menggunakan aplikasi ini untuk membantu mempermudah pengguna layanan dalam melakukan survey kepuasan pengguna layanan, dan dapat membantu pihak KPPN Bengkulu dalam mendapatkan informasi dari survei kepuasan pengguna layanan.

\section{DAFTAR PUSTAKA}

Fathansyah. 2012. Basis Data Edisi Revisi. Penerbit Informatika : Bandung.

Harto, Budi. 2015. Analisis Tingkat Kepuasan Pelanggan Dengan Pendekatan Fuzzy

Servqual Dalam Upaya Peningkatan Kualitas Pelayanan. Jurnal TEKNOIF Vol.3

No.1 April 2015. ISSN : 2338-2724

Hidayatullah, Priyanto. Kawistara, Jauhari Khairul. 2017. Pemrograman Web Edisi

Revisi. Penerbit Informatika : Bandung.

Intan, Rolly, dkk. 2015. Intellegence In The Era Of Big Data. Springer.

Lubis, Adyanata. 2016. Basis Data Dasar Untuk Mahasiswa Ilmu Komputer. Yogyakarta. Penerbit Deepublish. $123 \mathrm{Hal}$

Mujilan, Agustinus. 2013. Analisis dan Perancangan Sistem Perspektif Kompetensi Akuntansi Edisi 1. Madiun. Universitas Widya Mandala. $60 \mathrm{Hal}$.

Ramadhan, Arief. 2007. Student Guide Series Macromedia Dreamweaver 8. PT. Elex Media Komputindo : Jakarta

Sutabri, Tata. 2012. Analisis Sistem Informasi. Yogyakarta. Penerbit Andi. 160 Hal 